\title{
The Total Quality Management Analysis of Petroleum University Undergraduate Teaching Based on AHP Method
}

\author{
Tingting Wang \\ School of Electrical Engineering \& Information \\ Northeast Petroleum University \\ Daqing, China \\ wttlovework@163.com
}

\author{
Keyong Shao \\ School of Electrical Engineering \& Information \\ Northeast Petroleum University \\ Daqing, China \\ shaokeyong@tom.com
}

\begin{abstract}
Petroleum university undergraduate teaching faced major oil companies demand, according to the development of the industry to provide new teaching mode, a comprehensive quality management of petroleum university undergraduate teaching is the main trend of petroleum university teaching reform. In this paper, combining the characteristic of the proposed analysis method of total quality management of petroleum university undergraduate teaching based on the AHP(Analytic hierarchy process) method, establishing an analytic hierarchy model to monitor the effectiveness of TQM dynamically, and the model parameters can be adjusted in order to realize a strong practical and guiding significance for petroleum university.
\end{abstract}

Keywords-petroleum university; Undergraduate teaching; total quality management; analytic hierarchy process $(A H P)$

\section{INTRODUCTION}

The study of management idea and management technology of TQM (Total Quality Management, TQM) [1, 2] in the process of teaching management in colleges and universities is less. How to apply total quality management thought to the petroleum college quality monitoring and security system according to the particularity of petroleum college teaching management activities, so as to enhance the teaching quality and teaching competence of petroleum colleges and universities has become the research hotspot at present.

Total quality management of petroleum university undergraduate teaching means, petroleum universities take the quality as the center, on the basis of the teachers and students participation, the purpose of management is to achieve successful management way through the consumer satisfaction and higher benefit all members.

The research trend of teaching management in colleges and universities mainly include:

1) Establish a new evaluation mechanism; pay more attention to the supervision function.

2) Pay attention to quality education, to emphasize the Total Quality Management of undergraduate teaching. Teaching management is the management of the staff participation, the whole process, the all factors affecting the quality of teaching, and the quality management to comprehensive development and sustainable development of all students.

3) Reform the education administrative management team, optimize the distribution of staff, improve the efficiency of management. In this context, how to guarantee the quality and efficiency of management, total quality management of teaching provides a new way for us.

4) Advocate subjectivity management; emphasize the people-oriented management. Effective educational management must be based on the management of people.

AHP (Analytic hierarchy process) is a hierarchical weighted decision analysis method made by the United States operations researcher Thomas L. Saaty using network system theory and multi-objective comprehensive evaluation method. This method uses less quantitative information to solve the complex decision problems, make accurate decision and judgment for complex system.

According to the nature of the problem and the overall goal, analytic hierarchy process is divided into different constituent elements, and the elements of the interrelated effects of affiliation to the factors are combined according to different levels, forming a multi-layered structural model, thus the problem comes down to the bottom (for decision scheme, measures etc.) relative to the top (target) is relatively important in determining the weights of relative superiority or scheduled order.

\section{BASIC STEPS OF AHP}

Use analytic hierarchy process (AHP) to solve the problem of practical application, which can be roughly divided into the following four steps:

1) Establish the hierarchical structure model.

2) Constructing judgment matrix.

3) Calculate the weight vector, do the level of single sort, and do the consistency test.

4) Calculate the combination weights vector, do the level of total order, and combined consistency test. 


\section{APPLICATION OF ANALYTIC HIERARCHY PROCESS IN THE COMPREHENSIVE MANAGEMENT OF TEACHING QUALITY}

The implementation of total quality management in a petroleum university is to improve the quality of teaching, promote the school competitiveness. Total quality management emphasizes the whole target, whole process, and all staff participation, in order to check the each undergraduate professional teaching effect in implement total quality management, in order to better tracking effect, it is necessary to evaluate the implementation of total quality management in various professional teaching.

\section{A. Description of the Problem and the Hierarchical Structure Model}

In order to improve the teaching management quality in a petroleum university, we decide to implement total quality management in the university. The university has 5 teaching professions involved in total quality management system, through the research and analysis, constructs total quality management model in reference [3], as shown in Figure 1.

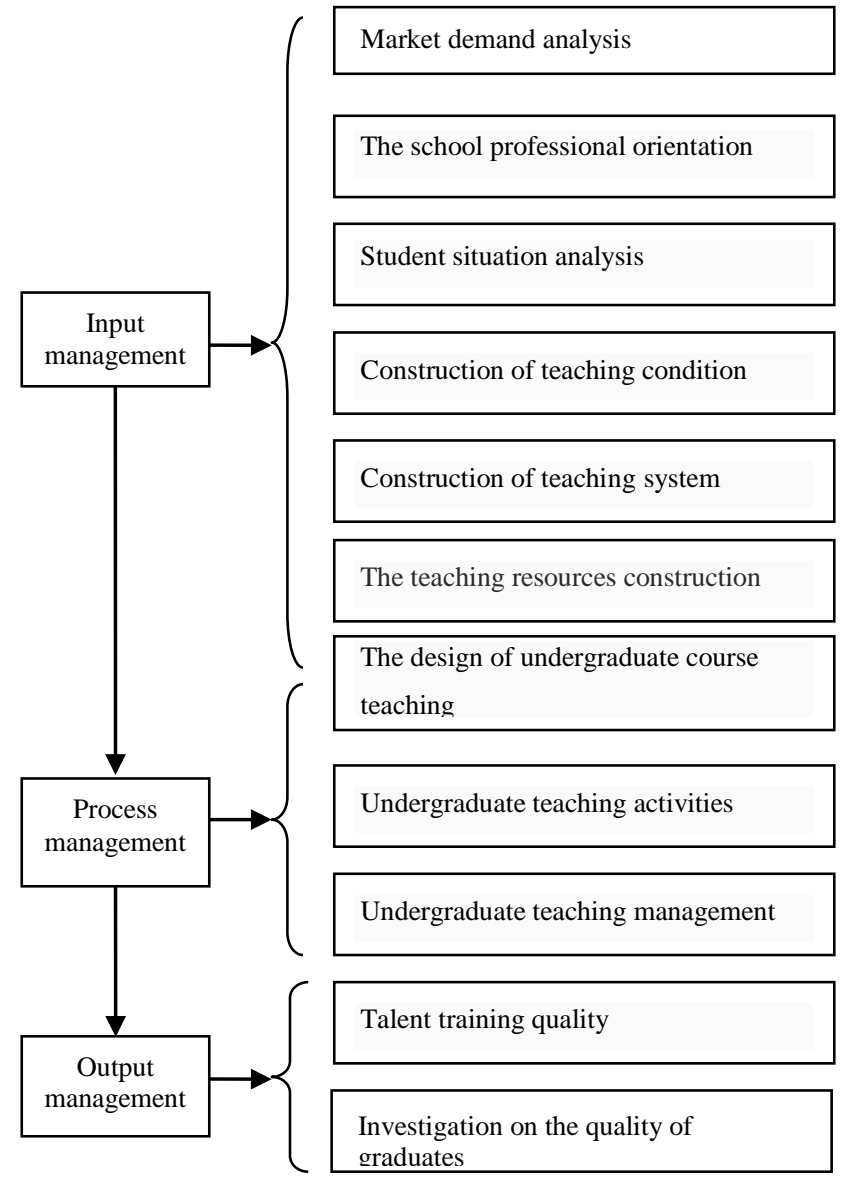

FIGURE I. TOTAL QUALITY MANAGEMENT MODEL

\section{B. Construct Judgment Matrix}

In this paper, using the scaling method [4], according to the requirements of the petroleum colleges and universities education and development goals, school experienced teaching personnel and management personnel compare the teaching input, teaching process and teaching output to get the judgment matrix of standard $\mathrm{C}$ relative to the target layer $\mathrm{G}$.

$$
A_{G-C}=\left[\begin{array}{ccccccccc}
1 / 4 & 1 & 1 / 9 & 1 / 2 & 1 / 6 & 2 & 1 / 2 & 8 & 3 \\
7 & 6 & 1 / 2 & 1 / 5 & 1 / 8 & 2 & 1 / 4 & 1 / 7 & 3 \\
1 / 4 & 4 & 5 & 1 / 6 & 4 & 1 / 8 & 6 & 1 / 5 & 1 \\
6 & 9 & 1 / 4 & 1 / 8 & 1 & 1 / 2 & 3 & 1 / 6 & 4 \\
1 & 8 & 1 / 9 & 1 / 5 & 7 & 1 / 4 & 1 & 2 & 1 / 2 \\
4 & 1 / 2 & 1 / 5 & 9 & 1 / 7 & 4 & 1 / 3 & 6 & 2 \\
1 & 4 & 1 / 8 & 1 / 9 & 5 & 1 / 6 & 1 & 2 & 1 / 5 \\
1 / 7 & 1 & 1 / 3 & 2 & 1 / 6 & 6 & 1 / 4 & 1 / 7 & 1 / 9 \\
1 / 5 & 4 & 1 / 6 & 9 & 8 & 1 / 7 & 1 & 2 & 3
\end{array}\right]
$$

Relative to the rule layer $\mathrm{C} 1$ : the school professional orientation, five teaching professions are not exactly the same, its position from high to low in turn is: the first profession, third profession, fourth profession, fifth profession, second profession, it can set solution layer $\mathrm{P}$ relative to the criteria of $\mathrm{C} 1$ judgment matrix.

$$
A_{C_{1}-P}=\left[\begin{array}{ccccc}
5 & 1 / 4 & 3 & 1 / 9 & 2 \\
1 & 4 & 1 / 5 & 1 & 2 \\
1 / 6 & 5 & 1 / 4 & 1 & 9 \\
1 / 5 & 1 & 3 & 2 & 1 / 8 \\
1 / 7 & 1 / 8 & 1 / 4 & 3 & 2
\end{array}\right]
$$

Relative to the rule layer C2: Students situation analysis, five teaching professions emphasis in the order: the second profession, fourth profession, first profession, fifth profession, third profession, it can set solution layer $\mathrm{P}$ relative to the criteria of $\mathrm{C} 2$ judgment matrix.

$$
A_{C_{2}-P}=\left[\begin{array}{ccccc}
1 & 1 / 3 & 3 & 8 & 2 \\
2 & 8 & 1 / 5 & 5 & 2 \\
1 / 5 & 3 & 1 / 4 & 3 & 1 \\
4 & 2 & 7 & 2 & 1 / 4 \\
1 / 7 & 1 / 6 & 4 & 5 & 9
\end{array}\right]
$$

Relative to the rule layer C3: Construction of teaching condition, five teaching professions emphasis in the order: the fourth profession, second profession, third profession, fifth profession, first profession, it can set solution layer $\mathrm{P}$ relative to the criteria of $\mathrm{C} 3$ judgment matrix.

$$
A_{C_{3}-P}=\left[\begin{array}{ccccc}
4 & 1 / 3 & 5 & 6 & 1 / 2 \\
2 & 1 / 9 & 6 & 4 & 7 \\
1 / 4 & 8 & 1 / 5 & 1 / 9 & 6 \\
1 / 3 & 2 & 1 / 7 & 5 & 1 / 4 \\
1 / 3 & 8 & 5 & 1 / 4 & 3
\end{array}\right]
$$

After a similar analysis and investigation, it can be concluded that solution layer $\mathrm{P}$ relative to the standards of all judgment matrix are as follows. 


$$
\begin{aligned}
& A_{C_{4}-P}=\left[\begin{array}{ccccc}
5 & 7 & 1 / 5 & 8 & 2 \\
9 & 1 / 8 & 5 & 1 / 8 & 1 / 2 \\
1 / 5 & 9 & 1 & 7 & 1 / 5 \\
4 & 1 / 2 & 1 / 8 & 2 & 2 \\
5 & 4 & 1 / 2 & 1 & 7
\end{array}\right] \\
& A_{C_{5}-P}=\left[\begin{array}{ccccc}
8 & 2 & 3 & 1 / 5 & 9 \\
1 / 2 & 1 / 6 & 5 & 7 & 1 \\
5 & 7 & 1 / 4 & 3 & 6 \\
1 / 4 & 2 & 1 / 9 & 2 & 8 \\
8 & 1 / 4 & 7 & 1 / 8 & 9
\end{array}\right] \\
& A_{C_{6}-P}=\left[\begin{array}{ccccc}
9 & 1 / 3 & 5 & 1 / 6 & 1 / 8 \\
1 / 2 & 6 & 1 / 6 & 4 & 7 \\
1 / 4 & 1 / 8 & 7 & 1 / 9 & 8 \\
6 & 2 & 1 / 7 & 2 & 1 / 8 \\
1 / 8 & 7 & 1 / 6 & 9 & 5
\end{array}\right] \\
& A_{C_{7}-P}=\left[\begin{array}{ccccc}
5 & 4 & 1 / 9 & 4 & 1 / 2 \\
1 & 1 / 8 & 3 & 1 / 6 & 1 / 7 \\
1 / 5 & 1 & 2 & 1 / 5 & 9 \\
8 & 1 / 4 & 1 / 2 & 6 & 1 / 8 \\
1 / 9 & 9 & 4 & 1 / 3 & 7
\end{array}\right] \\
& A_{C_{8}-P}=\left[\begin{array}{ccccc}
1 / 7 & 9 & 4 & 1 / 6 & 8 \\
5 & 2 & 1 / 3 & 4 & 1 / 9 \\
8 & 1 / 7 & 4 & 1 / 6 & 1 / 5 \\
1 / 2 & 1 & 3 & 1 / 9 & 1 / 8 \\
7 & 1 / 5 & 2 & 1 & 5
\end{array}\right] \\
& A_{C_{9}-P}=\left[\begin{array}{ccccc}
7 & 1 / 9 & 8 & 1 / 9 & 1 / 6 \\
1 / 3 & 1 & 1 / 6 & 2 & 3 \\
1 & 1 / 7 & 5 & 1 / 8 & 4 \\
9 & 1 / 6 & 3 & 1 / 2 & 6 \\
1 / 4 & 5 & 1 / 4 & 7 & 1 / 8
\end{array}\right]
\end{aligned}
$$

\section{Calculate the Weight Vector and the Level of Single Order}

According to the structure of the judgment matrix, using the method of root [5], the corresponding eigenvectors can be obtained, the maximum characteristic root and random consistency ratio.

For the judgment matrix AG-C, the characteristic vector is:

\section{$\alpha=\left(\begin{array}{llllll}0.0328 & 0.0143 & 0.2261 & 0.0353 & 0.0986 & 0.3176\end{array}\right.$ $\begin{array}{llll}0.0447 & 0.0624 & 0.1670) \mathrm{T}\end{array}$}

The biggest characteristic root is $\lambda \max =9.6425$,C.R. $=$ 0.0321

The AG-C has a satisfactory consistency, hierarchical single sorting is effective.

For judgment matrix ACi-P, $(\mathrm{i}=1,2,3,4,5,6,7,8,9)$,the biggest characteristic root is $\lambda \max (i)$,the feature vectors is $w(i)$.

The calculation result shows that judgment matrix AC1$\mathrm{P}, \mathrm{AC} 2-\mathrm{P}, \mathrm{AC} 3-\mathrm{P}, \ldots \ldots, \mathrm{AC} 9-\mathrm{P}$ has the consistency, the hierarchical single sorting is effective.

Finally, in the process of implementation of total quality management evaluation, the five teaching profession recommendation ranking from high to low in turn is: the fourth profession, third profession, fifth profession, second profession, first profession.

To be sure, in the evaluation process, selection of judgment matrix is of certain subjectivity, it needs the opinions of many relevant experts and the teaching management staff, to get more objective evaluation results.

\section{RESULTS}

The paper set up hierarchical analysis model for the petroleum universities and colleges of undergraduate course teaching to implement total quality management problem, based on the basic theory of hierarchical analysis model, evaluated the total quality management of teaching in colleges and universities, with examples in detail elaborated the analytic hierarchy process (AHP) in the evaluation model is built and the specific application.

\section{ACKNOWLEDGEMENTS}

This research was financially supported by the key Topic of Heilongjiang Province of China (Grant NO. GBB1212018).

\section{REFERENCES}

[1] Zhu Xiaowen. General total quality management to explore colleges and universities [J]. Education and vocational,2010, 12:46-47

[2] Wen Longguang. ZMJ company total quality management research [D].ChangSha: Central south university degree thesis, 2012

[3] Zhou Maodong. In institutions of higher learning is introduced into the analysis of total quality management [J].Journal of guangdong university of technology, 2010, 8(2):5-7, 12

[4] Huang Guanhong,Fang Gang. System engineering method and application [M].Guang Zhou: Jinan university press,2005

[5] Liang Jun, Zhao Yong. Introduction to system engineering [M]. Beijing: chemical industry press, 2005 